\title{
A New Perspective on a Morphological Confirmation of the Tissue Repair Process in the Experimental Simulation of a Surgical Dental Extraction in Rats
}

\author{
Arpine B. Antonyan; Dmitriy Yu. Kharitonov, PhD, ScD; Anna V. Podoprigora, PhD, ScD*; \\ Iliya V. Stepanov, PhD, ScD; Oleg Yu.Shalaev, PhD, ScD; Irina A. Belenova, PhD, ScD; \\ Elena A. Lecsheva, PhD, ScD; Alik E. Petrosyan
}

Voronezh State Medical University named after N.N. Burdenko Voronezh, the Russian Federation

\begin{abstract}
All stages of a surgical dental extraction are accompanied by risks of various complications. Many ways and methods have been created in order to prevent the development of complications of different genesis. However, this issue still remains relevant since dental surgeons face the challenge of inflammation problems during the post-extraction period. The use of male Wistar rats as a model organism for a surgical extraction of a lower incisor allows us to conduct visual, histological and immunohistochemical evaluations of the wound healing process.

The main objective of this study was to compare the effect of ionic silver solution and hydrogen water in high concentration when irrigating the operational field of a surgical dental extraction on the lower jaw.

The results obtained showed that the use of water with an increased content of molecular hydrogen during the treatment is able to stimulate the recovery of the EM of the connective periodontal tissue to a greater extent than the ionic silver solution, connected to the participation of MCs and their secretome.(International Journal of Biomedicine. 2021;11(2):164-168.)
\end{abstract}

Key Words: dental extraction $\bullet$ ionic silver solution $\bullet$ inflammatory complications $\bullet$ hydrogen water $\bullet$ mast cell

For citation: Antonyan AB, Kharitonov DYu, Podoprigora AV, Stepanov IV, Shalaev OYu, Belenova IA, Lecsheva EA, Petrosyan AE. A New Perspective on a Morphological Confirmation of the Tissue Repair Process in the Experimental Simulation of a Surgical Dental Extraction in Rats. International Journal of Biomedicine. 2021;11(2):164-168. doi:10.21103/Article11(2)_OA8

\section{Abbreviations}

MC, mast cell; CT, connective tissue; EM, extracellular matrix; RF, reticular fiber

\section{Introduction}

Annually, a large number of ways and methods are proposed in order to prevent the development of inflammatory complications. Nevertheless, according to statistics, the

*Corresponding author: Prof. Anna V. Podoprigora, PhD, ScD. Department of Maxillofacial Surgery, Voronezh State Medical University named after N.N. Burdenko. Voronezh, Russia. E-mail: ovses@yandex.ru number of complications does not decrease. This indicates that the proposed drugs are ineffective and the technique imperfect, both of which require adjustments and modifications.

To date, the solution to prevention and treatment of complications after a surgical dental extraction on the lower jaw is considered a pressing issue..$^{(1-5)}$

The main objective of this study was to compare the effect of ionic silver solution and hydrogen water in high concentration when irrigating the operational field of a surgical dental extraction on the lower jaw. 


\section{Material and Methods}

The study was performed on male Vistar rats, weighing $180 \pm 25 \mathrm{~g}$. The experiment was conducted on the basis of a certified vivarium of the Research Institute of Experimental Biology and Medicine at the Voronezh State Medical University.

The surgical dental extraction of the lower incisor was performed in laboratory rats in three study groups. In Group 1 $(\mathrm{n}=10)$, the operating field was irrigated with saline solution, and in Group $2(\mathrm{n}=10)$ - with ionic silver solution in a concentration of $20 \mathrm{mg} / \mathrm{l}$, using utility model No.183521, and in Group 3 $(\mathrm{n}=10)$ - with high-concentration $(8 \mathrm{ppm})$ of hydrogen water. In the control group of intact animals $(\mathrm{n}=10)$, the periodontal tissues of their lower incisors were examined without a tooth extraction procedure.

We conducted histochemical and immunomorphological studies of the periodontium of the lower incisors of the rats (gum, periodontal fibers) and soft tissues in the area of the CT of the alveolar processes in the intact animals and after removal of one of the incisors.

The sections were studied using a ZEISS Axio Imager A2 microscope. The total number of MCs was calculated with a $\times 40$ lens. Using the ImageJ program, microphotographs of the tissue specimen were utilized to measure the periodontal area of the lower incisors of the rats and soft tissues of the CT of the alveolar processes. Next, visually, depending on the technique used, we calculated the number of MCs (mastocytes), their colocalization with RFs, fibroblasts, MCs, and the number of myofibroblasts. The data obtained as a result of measuring all microphotographs of the tissue specimen were summed up and the amount of the above criteria per $1 \mathrm{~mm}^{2}$ area of CT was calculated.

Statistical analysis was performed using the Statistica 6.1 software package (Stat-Soft Inc., USA). The normality of distribution of continuous variables was tested by the Kolmogorov-Smirnov test. The mean (M) and standard deviation (SD) were calculated. Means of 2 continuous normally distributed variables were compared by independent samples Student's t test. Mann-Whitney U test was used to compare means of 2 groups of variables not normally distributed. For multiple comparisons, the Bonferroni correction was used.

\section{Results and Discussion}

The estimation of the MC population for periodontal and interalveolar CT of rats showed a significant increase after tooth extraction (Table 1). On Day 3 of the experiment, the increase in the $\mathrm{MC}$ number exceeded similar indicators in the control group, reaching the maximum in Group 2. On Day 7 of the experiment, in Group 1 the amount of MCs decreased slightly, compared to the previous observation period. At the same time, in Group 2, there was a further noticeable increase, in comparison with the parameters of Day 3 of the experiment. We observed a similar increase in the number of MCs in Group 3. On Day 14 of the experiment, an increase in the MC population was observed only in Group 3. Despite the decrease in the number of MCs by Day 14 of the experiment in Group 2, the MC population exceeded this indicator in Group 1. It should be noted that the size of the MCs in the studied tissues increased as the experiment continued.

Table 1.

The number of MCs (per $\mathrm{mm}^{2}$ ) in the rats periodontal membrane (May-Grünwald stain)

\begin{tabular}{|l|c|c|c|}
\hline $\begin{array}{c}\text { Observation } \\
\text { period }\end{array}$ & Group 1 & Group 2 & Group 3 \\
\hline \multicolumn{4}{|c|}{$\begin{array}{c}\text { Control group } \\
4.6 \pm 0.3\end{array}$} \\
\hline Day 3 & $10.4 \pm 1.1^{*}$ & $11,1 \pm 1,8^{*}$ & $8.4 \pm 0.6^{*}$ \\
\hline Day 7 & $7.2 \pm 0.5^{*}$ & $16.8 \pm 1.1^{*}$ & $13.2 \pm 1.3^{*}$ \\
\hline Day 14 & $11.3 \pm 1.5^{*}$ & $14.2 \pm 0.9^{*}$ & $20.3 \pm 1.7^{*}$ \\
\hline
\end{tabular}

Thus, each group has its own characteristics in the dynamics of the number of MCs in the periodontal region near the wound. In general, the main changes were associated with an increase in the number of MCs, which began to accumulate to a greater extent in the $\mathrm{CT}$ of the periodontal region adjacent to the location of the removed tooth. With an increasing duration of the post-extraction period, mastocytes increased in size and acquired a more pronounced metachromasia.

When assessing the secretory activity of the MCs, certain patterns were revealed, along with the general tendency to increase during different treatment protocols for laboratory animals. In particular, on Day 3 of the experiment, the maximum secretory activity was observed in Group 2 (Table 2, Fig. 1). By Day 7, the activity of MC degranulation decreased slightly, but by Day 14, we detected its increase again, with the highest intensity in Group 1. In accordance with the increased removal of the secretome into the EM of periodontal CT, the number of nondegranulated forms in the MC population decreased (Table 2).

Table 2.

Degranulation activity (\%) of the mastocydes in rats periodontium (May-Grünwald stain)

\begin{tabular}{|l|c|c|c|c|c|c|c|c|}
\hline \multirow{2}{*}{$\begin{array}{c}\text { Observation } \\
\text { period }\end{array}$} & \multicolumn{2}{|c|}{$\begin{array}{c}\text { Control } \\
\text { group }\end{array}$} & \multicolumn{2}{c|}{ Group 1 } & \multicolumn{2}{c|}{ Group 2 } & \multicolumn{2}{|c|}{ Group 3 } \\
\cline { 2 - 9 } & $\mathrm{D}$ & $\mathrm{nD}$ & $\mathrm{D}$ & $\mathrm{nD}$ & $\mathrm{D}$ & $\mathrm{nD}$ & $\mathrm{D}$ & $\mathrm{nD}$ \\
\hline & 53.7 & 46.3 & & & & & & \\
\hline Day 3 & & & 75.4 & 24.6 & 84.2 & 15.8 & 70.3 & 29.7 \\
\hline Day 7 & & & 72.3 & 27.7 & 78.2 & 21.8 & 68.4 & 31.6 \\
\hline Day 14 & & & 85.6 & 14.4 & 77.2 & 22.8 & 76.8 & 23.2 \\
\hline
\end{tabular}

$D$ - degranulated MCs, $n D$ - non-degranulated MCs

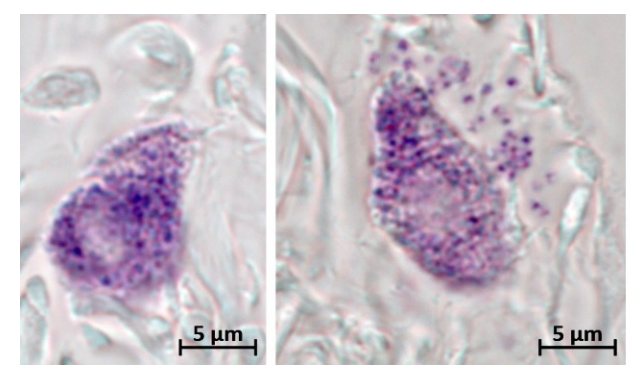

Fig. 1. MCs of the periodontium in the area of the anterior incisors of the rat. Fixative: 10\% neutral buffered formalin. Staining technique: Giemsa stain solution. A - the control group. Mast cell without signs of degranulation. B-Group 2, Day 3 of the experiment. Signs of active degranulation towards the incisor resection area. 
When assessing the level of tryptase expression in the MCs, we found that after incisor resection, there was a significant increase in the content of specific protease in all experimental groups, with the highest degree in Group 2. In Group 3, the content of tryptase-positive MCs was the lowest, despite exceeding the control parameters by more than two times (Table 3). A week after dental extraction, the number of tryptase-positive MCs continued to increase in Groups 2 and 3, while in Group 1 it decreased.

After two weeks of the experiment, we could note the preservation of an increased population of tryptase-positive MCs in the CT of the periodontium and the interalveolar region. At the same time, the highest expression of tryptase was observed in Group 3 using water enriched with molecular hydrogen (Table 3, Fig. 2), while in Group 2 the number of protease decreased slightly, compared to the previous followup period. The lowest number of tryptase-positive MCs by Day 14 was found in Group 1, compared to other experimental animals (Table 3 ).

Table 3.

The number of tryptase-positive MCs in periodontium of the rats $\left(\right.$ per $\left.\mathrm{mm}^{2}\right)$

\begin{tabular}{|c|c|c|c|}
\hline $\begin{array}{l}\text { Observation } \\
\text { period }\end{array}$ & Group 1 & Group 2 & Group 3 \\
\hline \multicolumn{4}{|c|}{$\begin{array}{c}\text { Control group } \\
2.2 \pm 0.1\end{array}$} \\
\hline Day 3 & $8.6 \pm 0.7$ & $10.1 \pm 0.8^{*}$ & $5.5 \pm 0.8^{*}$ \\
\hline Day 7 & $6.1 \pm 0.5$ & $14.2 \pm 1.2^{*}$ & $10.7 \pm 1.4^{*}$ \\
\hline Day 14 & $9.3 \pm 1.1$ & $12.7 \pm 1.1^{*}$ & $15.4 \pm 1.3 *$ \\
\hline
\end{tabular}

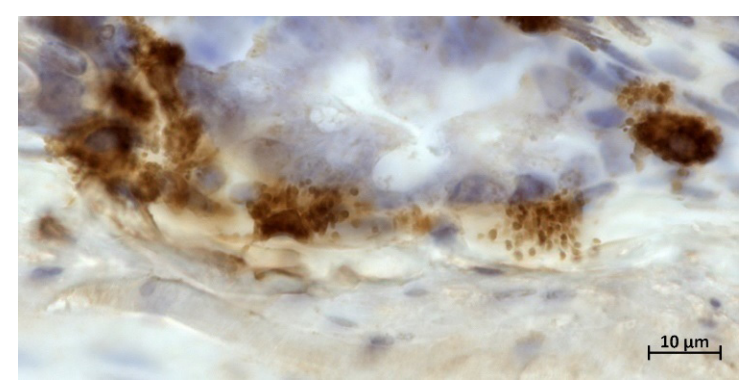

Fig. 2. Mast cells in the periodontium after resection of the rat incisor. Group 3, Day 14 of the experiment. Fixative: $10 \%$ neutral buffered formalin. Method: immunohistochemical staining for tryptase.

The study of colocalization of the MCs with RFs showed low numbers in general (Table 4). The MCs were mainly colocalized with mature collagen fibers forming multidirectional bundles, and much less often with thin RFs. However, by Day 3 of the post-resection period, an increase in the frequency of MC colocalization with RFs was revealed several times (Table 4). The highest numbers were achieved in Group 3 (Table 4, Fig. 3). More than half of the MCs were in close contact with RFs. The colocalization of RFs and MCs in Groups 1 and 2 was approximately equal and more than three times more frequent than in the control animals.
Table 4.

Colocalization of the mast cells and reticular fibers (in \%) in the connective tissue of the rat periodontium

\begin{tabular}{|l|c|c|c|}
\hline $\begin{array}{c}\text { Observation } \\
\text { period }\end{array}$ & Group 1 & Group 2 & Group 3 \\
\hline \multicolumn{4}{|c|}{$\begin{array}{c}\text { Control group } \\
\text { 12.2 }\end{array}$} \\
\hline Day 3 & 45.2 & 42.5 & 57.4 \\
\hline Day 7 & 58.2 & 53.4 & 83.2 \\
\hline Day 14 & 60.5 & 68.2 & 65.2 \\
\hline
\end{tabular}

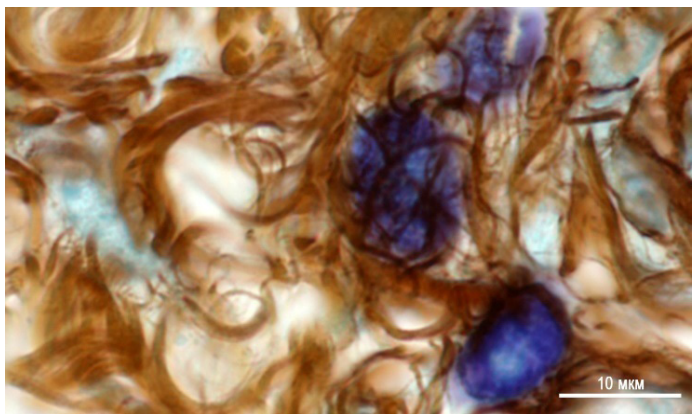

Fig. 3. The periodontium after resection of the rat incisor. Method: combined staining of Toluidine blue and silver impregnation. Group3, Day 14 of the experiment. There is a close colocalization of the mast cells and reticular fibers.

Seven days after dental extraction, the process of fibrillogenesis remained active, which was manifested by more frequent colocalization of MCs and RFs, compared to the control animals (Table 4). At the same time, the use of hydrogen water in the treatment protocol led to the highest frequency of detection of colocalization of the MCs and RFs in the CT of the Periodontium (Table 4).. In this experimental group,, the vast majority of MCs took part in fibrillogenesis (Table 4). Smaller and approximately equal numbers of the MCs and RFs were found in Groups 1 and 2, showing small effects of the solution in Group 2 from untreated animals on the fibrillogenesis involving MCs. By Day 14 of the post-resection period, in all experimental groups the fibrillogenesis involving MCs was approximately equalized, but remained much higher than in control animals. Thus, we can assume an increase in the fiber formation of the EM of the connective periodontal tissue with the participation of MCs. This process reaches maximum activity when using water enriched with molecular hydrogen after 7 days of the post-resection period.

From the point of view of intra-population, intercellular communication of MCs, it is necessary to note rather low indicators in the group of intact animals. However, after dental extraction, the intensity of intercellular communication of MCs with each other significantly increases, to the greatest extent in Group 2 (Table 5). The highest level in the aspect of intercellular signaling of MCs appears after 7 days in Group 3 (Table 5). At the same time, the indicators are almost 6 times higher than the levels in the control group. However, after 14 days, this effect is leveled, and the maximum frequency of attachment of MCs to each other is preserved in Group 2. 
Table 5.

The frequency of intra-population intercellular communication of MCs (\%) in the connective tissue of the periodontium

\begin{tabular}{|l|c|c|c|}
\hline $\begin{array}{c}\text { Observation } \\
\text { period }\end{array}$ & Group 1 & Group 2 & Group 3 \\
\hline \multicolumn{4}{|c|}{$\begin{array}{c}\text { Control group } \\
\text { 2.2 }\end{array}$} \\
\hline Day 3 & 3.4 & 5.2 & 4.4 \\
\hline Day 7 & 5.5 & 8.8 & 12.7 \\
\hline Day 14 & 4.8 & 6.3 & 5.4 \\
\hline
\end{tabular}

Therefore, the removal of the incisor is accompanied by an increase in the intensity of intercellular exchange in the MC population. This obviously affects the functional activity of the mastocytes, including the remodeling of the EM. In particular, this increase in intensity can be evidenced by the results of combined staining of MCs with Giemsa solution and impregnation with silver.

Judging by the frequency of colocalization of the MCs with fibroblasts, 3 days after tooth resection the highest parameter of this indicator was observed in the group using hydrogen water (Group 3) as an irrigation agent. At the same time, in the remaining groups, despite the lower parameters of this indicator, there was a significant increase, in comparison with the control level (Table 6, Fig.4). It should be noted that this indicator remains at the maximum level, in comparison with the other groups of the experiment, on both Days 7 and 14 . At the same time, the adherence of the MCs to fibroblasts was the lowest in Group 2 by Day 7 (Table 6).

Table 6.

The frequency of adherence of mast cells to fibroblastic differon cells in the periodontium of the lower incisors of rats (\%)

\begin{tabular}{|c|c|c|c|}
\hline $\begin{array}{l}\text { Observation } \\
\text { period }\end{array}$ & Group 1 & Group 2 & Group 3 \\
\hline \multicolumn{4}{|c|}{$\begin{array}{c}\text { Control group } \\
8.6\end{array}$} \\
\hline Day 3 & 16.7 & 15.2 & 25.3 \\
\hline Day 7 & 18.4 & 13.4 & 22.2 \\
\hline Day 14 & 15.6 & 17.2 & 20.4 \\
\hline
\end{tabular}

The number of the RFs in the group of intact animals was insignificant (Table 7). However, on Day 3 of the experiment, this indicator significantly increased with the highest parameters in Group 3 and continued to increase significantly, reaching a maximum by Day 14 (Table 7).

\section{Table 7.}

The number of the reticular fibers in the periodontium of the lower incisors of rats (c.u.)

\begin{tabular}{|l|c|c|c|}
\hline \multicolumn{1}{|c|}{$\begin{array}{c}\text { Observation } \\
\text { period }\end{array}$} & Group 1 & Group 2 & Group 3 \\
\hline \multicolumn{4}{|c|}{$\begin{array}{c}\text { Control group } \\
1.9\end{array}$} \\
\hline Day 3 & 7.7 & 6.2 & 9.7 \\
\hline Day 7 & 8.9 & 8.7 & 12.5 \\
\hline Day 14 & 8.7 & 7.1 & 17.4 \\
\hline
\end{tabular}

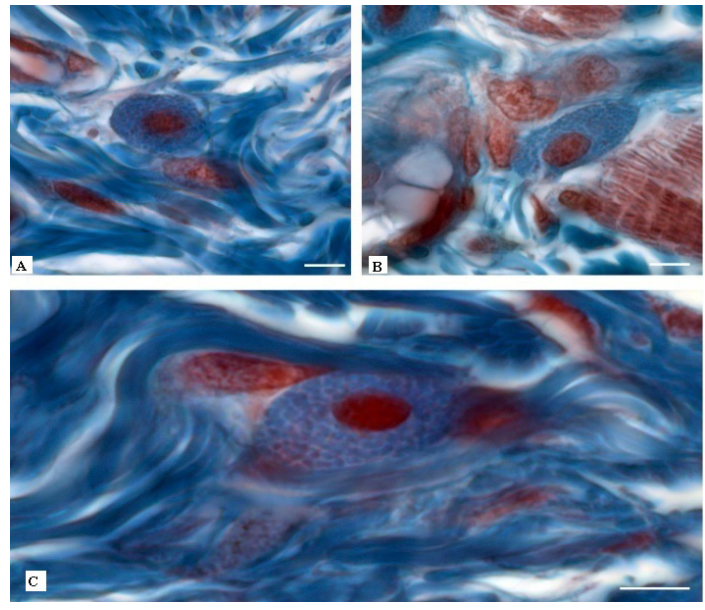

Fig. 4. Colocalization of the mast cells with fibroblasts after dental extraction of the incisor. Fixative: 10\% neutral buffered formalin. Method: staining with PicroMallory solution. A - Group 1, Day 3. B-Group 2, Day 7. C-Group 3, Day 14.

The number of fibroblasts in the periodontal $\mathrm{CT}$ is also consistent with these data. In particular, this indicator reached the maximum by Day 14 of the experiment in Group 3 (Fig. 5, Table 8). At the same time, this indicator showed high parameters in the first periods of observation in all groups, with the greatest level in Group 2. However, on Days 7 and 14, the highest number of myofibroblasts was found in Group 3.

Table 8 .

The number (c.u.) of myofibroblasts in the periodontium of the lower incisors of rats (staining with Picro-Mallory solution)

\begin{tabular}{|l|c|c|c|}
\hline $\begin{array}{c}\text { Observation } \\
\text { period }\end{array}$ & Group 1 & Group 2 & Group 3 \\
\hline \multicolumn{4}{|c|}{$\begin{array}{c}\text { Control group } \\
1.3\end{array}$} \\
\hline Day 3 & 5.5 & 12.3 & 8.4 \\
\hline Day 7 & 7.5 & 8.6 & 14.4 \\
\hline Day 14 & 12.3 & 7.7 & 17.3 \\
\hline
\end{tabular}

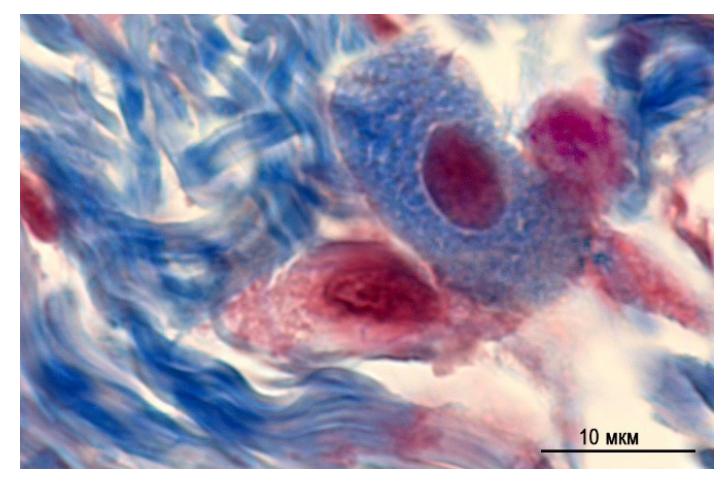

Fig. 5. The periodontium of the rat after removal of the incisor. Fixative: $10 \%$ neutral buffered formalin. Method: staining with Picro-Mallory solution. Colocalization of a mast cell with myofibroblast.

To explain the improvement in the regeneration of damaged tissues, we should consider the condition of CT, both fibrous and amorphous components. Among the criteria that can 
reflect the intensity of recovery of the intercellular matrix we noted the number of newly formed thin collagen fibers, as well as the participation of MCs in the issues of fibrillogenesis. ${ }^{(6)}$ It should be pointed out that the number of MCs in the CT of the periodontium increased significantly after resection, which is due to both the immunomodulatory effects of MCs and their regulatory properties in relation to the structures of the EM. It is obvious that the number of RFs in CT had certain differences depending on the treatment. It also should be noted that the highest numbers of RFs were found in the second, and especially in the third period of the experiment while using hydrogen water. The biological effects of molecular hydrogen on the enhancement of fibrillogenesis can be closely related to the activity of MCs, which are connected to the processes of the EM remodeling.

As a result of the analysis, it was revealed that different treatment protocols may have different effects on the state of collagen fibrillogenesis, which is the basis for the restoration of the CT framework. In particular, different treatments result in different levels of intercellular signaling of MCs, as well as MCs and fibroblasts within a specific periodontal tissue microenvironment. The adhesion of MCs to fibroblasts is a morphological confirmation of fibrillogenesis. This initiates the assembly of collagen fibrils and subsequently a fullfledged collagen fiber. It is also necessary to take into account the importance of the secretory activity of the MCs, which can change the physico-chemical properties of the integrative buffer medium. As a result of that, collagen molecules polymerize into supramolecular structures, fibrils and other stages of the organization of the collagen fiber.

Another important inductive signal for fibroblasts in terms of stimulating the biogenesis of collagen proteins is an increase in tryptase expression in MCs and secretion into EM. ${ }^{(6)}$ In addition, tryptase has important properties for initiating fibroblast differentiation into myofibroblasts, and the latter are known to have a much higher capacity for collagen biosynthesis ${ }^{(6)}$ Also, an increase in the level of tryptase in the EM can stimulate the division of myofibroblasts with their accumulation in a certain locus of $\mathrm{CT} .^{(7)}$

Furthermore, the interaction of MCs with fibroblasts is one of the mechanisms of EM remodeling, in which intercellular signaling is accompanied by the changes in the expression profiles of various EM proteins in fibroblasts. In addition, an inductive effect of the MCs on the mitotic activity of fibroblasts may increase their number per unit volume of tissue, as well as possible transformation into myofibroblastic cells.

Therefore, the use of water with an increased content of molecular hydrogen during the treatment is able to stimulate the recovery of the EM of the connective periodontal tissue to a greater extent than the ionic silver solution, connected to the participation of MCs and their secretome.

\section{Competing Interests} interests.

The authors declare that they have no competing

\section{References}

1. Dallaserra M, Poblete F, Vergara C, Cortés R, Araya I, Yanine N, Villanueva J. Infectious postoperative complications in oral surgery. An observational study. J Clin Exp Dent. 2020 Jan 1;12(1):e65-e70. doi: 10.4317/medoral.55982.

2. Malkawi Z, Al-Omiri MK, Khraisat A. Risk indicators of postoperative complications following surgical extraction of lower third molars. Med Princ Pract. 2011;20(4):321-5. doi: $10.1159 / 000324550$.

3. Shigeishi H, Ohta K, Takechi M. Risk factors for postoperative complications following oral surgery. J Appl Oral Sci. 2015 Jul-Aug;23(4):419-23. doi: 10.1590/1678775720150130 .

4. Sato J, Goto J, Harahashi A, Murata T, Hata H, Yamazaki Y, Satoh A, Notani K, Kitagawa Y. Oral health care reduces the risk of postoperative surgical site infection in inpatients with oral squamous cell carcinoma. Support Care Cancer. 2011 Mar;19(3):409-16. doi: 10.1007/s00520-010-0853-6.

5. Lodi G, Azzi L, Varoni EM, Pentenero M, Del Fabbro M, Carrassi A, Sardella A, Manfredi M. Antibiotics to prevent complications following tooth extractions. Cochrane Database Syst Rev. 2021 Feb 24;2:CD003811. doi: 10.1002/14651858. CD003811.pub3.

6. Atiakshin D, Buchwalow I, Tiemann M. Mast cells and collagen fibrillogenesis. Histochem Cell Biol. 2020 Jul;154(1):21-40. doi: 10.1007/s00418-020-01875-9.

7. Atiakshin D, Buchwalow I, Samoilova V, Tiemann M. Tryptase as a polyfunctional component of mast cells. Histochem Cell Biol. 2018 May;149(5):461-477. doi: 10.1007/ s00418-018-1659-8. 